\title{
Terceiro setor e interesses coletivos: as alternativas sociais na busca da cidadania
}

\author{
José Querino Tavares Neto ${ }^{1}$ \\ Aline Ouriques Freire Fernandes ${ }^{2}$
}

\begin{abstract}
Resumo: Os interesses da coletividade são a base, constituem as características fundamentais do Terceiro Setor enquanto ator no exercício da Cidadania. A crise Constitucional e Institucional do Estado que não alcança com eficácia a sua função social é o resultado do impacto causado pelos acontecimentos políticos e econômicos no decorrer dos séculos, o que atribuiu aos legitimados da Sociedade Civil intensas demandas sociais que anteriormente eram de titularidade do próprio Estado. As reflexões deste artigo concentram-se na dimensão da atuação do terceiro setor, sua função social, seus mecanismos de trabalho e políticas públicas utilizadas na busca dos caminhos que conduzam à cidadania.
\end{abstract}

Palavras-chave: Terceiro setor. Cidadania. Interesses coletivos.

\begin{abstract}
The interests of the community are the basis, the key features of the Third Sector as an actor in the exercising of citizenship. The crisis of the Constitutional and Institutional State that is not effectively reaching its social function is the result of the impact caused by political and economic events over the centuries which attributed to the legitimized of the Civil Society intense social demands that previously were belonging to the State itself. The reflections in this article are concentrated on the performance of the Third Sector, its social function, the mechanisms of work and public policies used in the search of the paths to citizenship.
\end{abstract}

Keywords: Third Sector. Citizenship. Collective Interests.

\footnotetext{
1 Professor adjunto da Faculdade de Direito da Universidade Federal de Goiás, do Mestrado em Direito da UNAERP, do Mestrado em Desenvolvimento Regional das Faculdades ALFA: realizou estágio pós-doutoral em Direito Constitucional pela Universidade de Coimbra com bolsa da Capes. Bolsista da Funadesp.E-mail: josequerinotavares@gmail.com

2 Mestranda em Direitos Coletivos, Cidadania e Função Social pela UNAERP Universidade de Ribeirão Preto, com bolsa da CAPES/PROSUP (início 2009). Especialista em Direito Tributário pela UNAERP - Universidade de Ribeirão Preto (2007). Advogada e consultora jurídica, com ênfase no Direito Tributário e Direito do Terceiro Setor. E-mail: alineoffernandes@globo.com
} 


\section{Introdução}

O cerne deste estudo está na questão da busca da cidadania pela Sociedade Civil em suas múltiplas acepções, como, por exemplo, os movimentos sociais, o terceiro setor, o Governo e Mercado. Nas últimas décadas, o surgimento e a busca pela afirmação de novas práticas que alcancem os interesses de todos, que procuram soluções efetivas para os problemas que afligem a humanidade, delinearam uma nova concepção de Direito e de solidariedade.

$\mathrm{O}$ grande desafio das ciências sociais no século $\mathrm{XX}$, sobretudo em sua segunda metade, foi (re) compor sua natureza e finalidade. Foi a constatação da necessidade de sair da seara do conceito, ir do estudo para a ação, com a visão de buscar alternativas válidas para os diversos problemas e assim perseguir o cumprimento de direitos atinentes aos cidadãos. Ali assistimos a tentativa de afirmação dos grandes paradigmas, que, diante das oportunidades reais de transformação da sociedade, procuravam afirmar, negando, cada um a seu modo, os contrapontos estrutural (classes, partidos, sindicatos, etc.) funcional (o sistema como determinante) e/ou economicista (a racionalidade do mercado).

Neste sentido, reveste-se de grande importância a presença do chamado Terceiro Setor enquanto "fenômeno que se expressa a partir de uma nova prática social concebida pelas múltiplas expressões da cidadania, cada vez mais planetária, na sociedade civil” (MONTOVANELLI JUNIOR, 2006, p. 41).

Numa sociedade cada vez mais globalizada, em meio à crise de identidade do Estado e do Mercado, atua o Terceiro Setor enquanto sociedade civil ativa, cumprindo um papel complementar à realidade. $\mathrm{Na}$ continuidade desses acontecimentos, o Terceiro Setor se mostra como o reflexo da impotência do Estado e Mercado em responder às necessidades democráticas postas numa cidadania cada vez mais planetária.

O estudo do Terceiro Setor está diretamente ligado aos interesses do povo, interesses sociais que, devido a sua essencialidade, são abraçados pelo direito e se refletem no mundo jurídico como a tutela constitucional dos direitos coletivos. Ainda mais estreita é a sua a relação com a 
Cidadania, por ser esta o conjunto de direitos e deveres do indivíduo inserido na sociedade.

Na conclusão desse pensamento, o ciclo está completo, pois o ideal maior de um Estado que professa um Governo Democrático é defender os interesses do seu povo, e o caminho para a obtenção desse objetivo é a educação dos seus homens e mulheres para que compreendam seus direitos e deveres para que possam exercer a Cidadania.

\section{Da filantropia à cidadania: a trajetória do Terceiro Setor e sua legitimação na seara coletiva}

\subsection{A inserção do terceiro setor na sociedade}

O Terceiro Setor tem ascendência sociológica e traça a diferença entre o Estado, Primeiro Setor, e o Setor Privado ou de Mercado, Segundo Setor. Rifkin (1997) apresenta uma divergência relevante quanto a essa divisão hierárquica por entender que a denominação correta seria Primeiro Setor pois defende que, historicamente, a Sociedade surgiu primeiro que o Estado e o Mercado. Contrapõe-se ao Primeiro e Segundo Setor e aposta numa nova forma de divisão da riqueza, que diverge da visão adotada pelo Estado e pelo Mercado porque tem como direção uma política altruísta, afirmativa, carregada de conceitos sociais que abrangem a coletividade.

Define-se por ser o conjunto de iniciativas privadas, de caráter público, sem fins econômicos que funcionam estruturalmente como associações e fundações destinadas diretamente ao atendimento do interesse público.

Segundo Fernandes (1994, p. 21), "trata-se de um conjunto de organizações e iniciativas privadas que visam à produção de bens e serviços públicos. Ou, ainda, a expressão de inúmeras ações de indivíduos, grupos e instituições que tem como fim suprir necessidades coletivas”.

Pontuar a sua origem histórica é de extrema relevância para o estudo em desenvolvimento porque a existência de instituições de cunho social não data do século XX. Os movimentos de transformação social advindos 
da reunião de pessoas para realizar um objetivo comum são registrados já nos séculos XVI e XVII. Inicialmente, a mola propulsora foi a religião, as obras assistenciais ; e a Igreja Católica, através do seu Clero, controlava de forma centralizadora as atividades, o seu alcance e a sua forma de atuação; posteriormente, os interesses políticos encontraram nesse tipo de associação grandes respostas para as falhas nos seus sistemas de governo e reforçaram a importância da participação da sociedade nesses setores.

Acontecimentos políticos como a era de ouro do liberalismo ${ }^{3}$ onde de um lado o livre poder para decidir e agir teve maior aceitação no mundo econômico e em suas teorias, e, por outro, o ideal democrático fundamentado nas teorias políticas era mais restrito porque tinha a visão do liberalismo como igualdade civil para a sociedade inserida no Estado, foram impulsionadores para delinear o novo papel das organizações da sociedade civil. Foi o chamado Welfare State, ou Estado do Bem Estar Social, Estado este com funções claras nas searas política, econômica e social que objetivavam sobremaneira conciliar a livre iniciativa liberal e garantir as liberdades individuais.Defendia que todo o indivíduo teria, em regra, o direito, desde seu nascimento, a um conjunto de bens e serviços que deveriam ser fornecidos diretamente através do Estado ou indiretamente, mediante seu poder de regulamentação, sobre a sociedade civil. Por conseguinte, as ideias defendidas pela Sociedade Civil organizada tiveram eco e as políticas públicas enquanto ações voltadas para a defesa e garantia dos interesses sociais encontraram seu espaço.

Na América Latina, surgia o movimento chamado de Constitucionalismo Social, fruto de grandes conquistas de uma sociedade organizada e que inseriu na Constituição do México, em 1917, os direitos dos trabalhadores, denominados Direitos Sociais. Esse conjunto de ideias embrionárias do Constitucionalismo Social que procurou equilibrar os Direitos Fundamentais com os Direitos Sociais, teve significativa

3 Segundo Miguel Reale (1998, p. 32), ao situar o liberalismo, não podemos olvidar que, por sua vez, o liberalismo político, cujo fundador foi reconhecidamente John Locke, no século XVII, só mais tarde iria convergir no sentido do liberalismo econômico, instituído primordialmente por Adam Smith, no século XVIII, compondo-se assim a díade democracia liberal destinada a assinalar o real triunfo da burguesia no século passado. 
repercussão nas instituições sociais da época por relacionar diretamente os Direitos da Coletividade com a Cidadania. ${ }^{4}$

Num outro quadro, a Segunda Guerra Mundial e suas consequências desastrosas adequaram os interesses das organizações da sociedade civil com as necessidades prementes do povo vitimizado. Como consequência, novas doutrinas políticas foram erguidas no intuito de justificar as ideias e encontrar resposta para os graves problemas econômico-sociais. Quanto aos países devastados, o que realmente interessava era a política de reconstrução e foi nesse espaço vazio que os agentes sociais organizados cumpriram o seu papel e justificaram na prática as suas ideologias coletivas.

O ápice desse traçado histórico de percepção do terceiro setor veio na década de 1960 com o período da Guerra Fria. Nas décadas seguintes, o declínio do Socialismo Real e o renascimento da doutrina liberal que hoje, após constantes evoluções de pensamento se transformou em Neoliberalismo ${ }^{5}$ exigiu das organizações uma postura política colocada para o desenvolvimento social com uma visão restauradora da Cidadania, definindo como missão maior a sua atuação em prol dos interesses coletivos da sociedade.

A consagração dos direitos sociais que integram os direitos fundamentais enquanto resultado de todo esse processo histórico ratifica a afirmação de que esses ultrapassam o interesse privado e o interesse do próprio Estado, traçando o que se pode chamar de responsabilidade coletiva, e essa se manifesta quando questões de fundo social passam a exigir a participação do Governo, da iniciativa privada e dos cidadãos que

4 No entender de Silva, (1999, p. 346-347), cidadania é o elemento que qualifica os participantes da vida do Estado, representando um atributo político das pessoas que fazem parte da sociedade e que lhes confere o direito de participar do governo e de serem ouvidas pela representação política.

5 Movimento que, a partir da década de 1980, nos governos de Ronald Reagan - EUA e Margareth Thacher na Inglaterra, retomaram o Estado minimalista, cuja ação se restringe ao policiamento, justiça e defesa nacional; que no Brasil se confirmou nos processos de privatização de organismo estatais e abolição de reserva de mercado; encontrando melhor resposta ainda com a crise do “socialismo real” no final dos anos 80. 
se conscientizaram da importância que representa a mobilização coletiva em busca da justiça social.

Casquete, ao descrever os direitos sociais através dos movimentos sociais testifica:

De acuerdo com esta función de detección de déficits, los movimientos sociales serlan expresión de inquietudes sociales que giran alrededor de aspectos no tomados em consideración, a menudo ni siquiera percebidos por los canales encargados de actuar de correa de transmisión y de elevar las demandas sociales a la esfera resolutiva de la política. (CASQUETE, 2006, p. 11). ${ }^{6}$

Para ele, o papel dos movimentos sociais $^{7}$ numa democracia não é suplantar os partidos políticos, mas enriquecer os canais de deliberação e exercer influência nas tomadas de decisões relevantes, o que denota uma verdade; afinal, o povo é o legítimo detentor do poder e é em nome dele que esse poder é exercido; eis o fio condutor para a sedimentação da atuação dos movimentos sociais de forma organizada e sua transformação no que hoje se denomina terceiro setor.

$\mathrm{Na}$ história do Brasil, as primeiras instituições documentadas que atuaram com filantropia e solidariedade, foram as Santas Casas de Misericórdia, impulsionadas pela força da Igreja Católica. Datam de 1534, em Santos, no estado de São Paulo, e 1738 no Rio de Janeiro.

6 De acordo com essa função de detecção dos déficits, os movimentos sociais seriam expressões de inquietudes sociais que giram em torno de aspectos não levados em consideração, muitas vezes nem percebidos por meio dos canais encarregados de atuar como instrumentos de levantamento e comunicação das demandas sociais à esfera resolutiva da política (Tradução livre).

7 Para Casquete, “Los movimientos sociales no están institucionalizados ni sus funciones recogidas em constitución u ordenamento jurídico alguno. Pertenecem más bien a la realidad de los modernos sistemas democráticos. Su mera existencia revela pues la insuficiência y el déficit de los mecanismos estabelecidos de representación de interesses y de valores” (2006, p. 17). Os movimentos sociais não estão institucionalizados, nem suas funções elencadas em constituição ou algum ordenamento jurídico. Pertencem muito mais à realidade dos modernos sistemas democráticos. Sua mera existência revela a insuficiência e o déficit dos mecanismos estabelecidos de representação de interesses e valores (Tradução livre). 
Todavia, as primeiras manifestações dignas de destaque como atuação precursora do terceiro setor são do período da introdução da Cruz Vermelha ${ }^{8}$ no Brasil e da fundação da Legião Brasileira de Assistência. ${ }^{9}$

Segundo Froes, a definição de terceiro setor

[...] surgiu já na primeira metade do século, nos Estados Unidos. Ele seria uma mistura dos dois setores econômicos clássicos da sociedade: o público, representado pelo Estado e o privado, representado pelo empresário em geral [...] No Brasil, o novo conceito é muito recente. As empresas que admitem suas responsabilidades sociais ainda são poucas. Cidadãos que trabalham por si próprios ainda são mais raros. Mas algumas organizações sociais já se destacam no desenvolvimento de projetos sociais em nosso país (FROES, 2002, p. 5).

O termo “Terceiro Setor” deu lugar às denominações até então utilizadas pelas organizações da sociedade civil, entendidas como entidades filantrópicas, de beneficência ou benemerência (entre outras), por ter uma abrangência maior e por advir do exemplo dos Estados Unidos, como se observa da tradução literal do vocábulo americano Third Sector, que faz referência não só as atividades de uma sociedade civil organizada como também às Non Profit Organizations, organizações sem fins lucrativos e ao Voluntar Sector, setor voluntário.

Esse novo setor da sociedade tem por característica essencial a criação de projetos para a realização de benefícios coletivos, ou seja, que atinjam ou possam atingir, dependendo da área de atuação da organização, um grande número de pessoas inseridas na missão desses projetos. Algumas promovem benefícios coletivos privados; são as que visam à

8 Comitê Internacional da Cruz Vermelha - Criado em junho de 1859 por Jean Henry Dunant, que, ao constatar o grande número de mortos na Batalha de Solferino, na Itália, percebeu que, se os civis e soldados feridos tivessem recebido socorro imediato, muitas vidas teriam sido poupadas. Deu início a sua militância e criou assim a Cruz Vermelha, presente hoje em todo o mundo e tida como marco histórico para os estudos do terceiro setor. No Brasil, o Comitê da Cruz Vermelha foi fundado em 1908 e o seu primeiro presidente foi o médico Joaquim de Oliveira Botelho.

9 LBA - Legião Brasileira de Assistência - Dec. Lei no 4.830 de 1942. 
ajuda mútua e defendem os interesses de um grupo restrito de pessoas sem que tenham um considerável impacto social; as de caráter público, por sua vez, estão focadas no atendimento dos interesses mais comuns da sociedade e por esse motivo produzem bens e serviços que agregam benefícios para toda a sociedade.

As organizações seguem uma estrutura associativa firmada em suas missões, objetivos e funções e, nesse sentido, dividem-se em áreas distintas de atuação, como a dos direitos difusos onde estão situadas as instituições que representam causas sociais, como a preservação ambiental, os direitos dos consumidores, a inclusão de minorias, os direitos da criança e do adolescente. De outra via, estão instituições com viés de promoção social e enfoque humanitário que apontam para o auxílio aos necessitados em seu conceito mais amplo (saúde, combate à fome e à miséria, educação), trabalham em parceria com as de direito difuso no intuito de viabilizar mudanças sociais. Existem ainda as instituições de benefício mútuo que lutam por interesses determinados; são os sindicatos, igrejas, partidos políticos, associações de bairro, entre outras. Por fim e não menos relevantes estão as instituições com o intuito de apoiar financeira, institucional, ideológica, técnica e gerencialmente as instituições de todas as áreas; exemplos clássicos são as fundações privadas e os institutos de pesquisa e serviços.

\subsection{A sociedade civil e o terceiro setor enquanto atores da legitimação dos interesses coletivos}

As últimas décadas foram motivo de destaque pelo veemente fortalecimento da sociedade civil, organizada devido a sua estrutura e aperfeiçoamento. As principais responsáveis por esse fortalecimento são as organizações não governamentais sem fins lucrativos, ${ }^{10}$ que preencheram lacunas antes existentes entre o Estado e a sociedade,

\footnotetext{
10 Há uma diferenciação na doutrina entre o termo "sem fim lucrativo" e "sem fim econômico". O primeiro diz respeito a não obtenção de qualquer lucro como resultado das atividades desenvolvidas pelas organizações; o segundo possui um alcance maior ao compreender que não tem fim econômico a instituição que reverte o resultado das suas atividades no desenvolvimento da sua missão e da própria organização. Atualmente, o termo sem fim econômico tem encontrado mais aceitação por permitir a aplicação dos
} 
seja por meio dos canais institucionais como os conselhos gestores e os orçamentos participativos, seja por meio da defesa e promoção de serviços sociais considerados básicos. As organizações obtiveram todo esse destaque porque os dois primeiros setores já definidos e solidificados não conseguiam responder às urgentes demandas sociais: $O$ Estado, por ineficiência ou insuficiência de adequação de suas políticas à realidade, e o mercado por objetivar diretamente as relações de lucro.

Mas o que é sociedade civil? De acordo com Bobbio:

Sociedade civil é o lugar onde surgem e se desenvolvem os conflitos econômicos, sociais, ideológicos, religiosos, que as instituições estatais têm o dever de resolver ou através mediação ou através da repressão. Sujeitos desses conflitos e, portanto da sociedade civil exatamente enquanto contraposta ao Estado são as classes sociais, ou mais amplamente os grupos, os movimentos, as associações, as organizações que a representam ou se declaram seus representantes; ao lado das organizações de classe, os grupos de interesses, as associações de vários gêneros com fins sociais, e indiretamente políticos, os movimentos de emancipação de grupos étnicos, de defesa dos direitos civis, de libertação da mulher, os movimentos de jovens, etc. (BOBBIO, 1987, p. 35-36).

O conceito de sociedade civil construído por Bobbio está presente na Carta Magna de 1988, que, ao dispor no Título II, Capítulo I, sobre os Direitos e Garantias Fundamentais e Coletivos demonstra um traço marcante do Direito Contemporâneo: focar o seu alcance nos interesses coletivos e mais especificamente nos interesses difusos, saindo portanto da esfera dos interesses de caráter individual.

O interesse coletivo tão próximo do ideiais do terceiro setor precisa ser compreendido em três acepções para ser corretamente definido. Em primeiro lugar, é interesse pessoal de um grupo, é o interesse da pessoa moral, que levou à formação do grupo em si mesmo como entidade autônoma e distinta dos seus membros; não é um interesse propriamente coletivo e é compreendido pela doutrina como um interesse social por ser

recursos na própria organização sem que isso caracterize desvio da função ou mau uso dos benefícios legais. 
direto, pessoal e pertinente àquele grupo determinado; logo, integra o seu patrimônio social, num sentido amplo.

Numa segunda percepção mais tradicional e consequentemende fechada, o interesse coletivo é tido como uma soma de interesses individuais; é coletivo na forma porque assim é exercido, mas, em sua essência, é individual por atender a necessidades individuais.

Por último, tem-se a visão de interesse coletivo como síntese de interesses individuais; nesse ponto, há uma mudança clara no entendimento, não se trata mais de uma simples defesa de interesses pessoais do grupo, tampouco de uma soma de interesses dos que integram o grupo. São interesses que ultrapassam os dois primeiros limites teóricos, que nascem a partir do momento em que interesses individuais atraídos por similaridades e harmonizados pelo fim comum se juntam aos interesses do grupo. Percebe-se que o termo ideal não é soma de interesses e sim síntese, porque os interesses coadunam-se ao visarem a um fim comum. ${ }^{11}$

Os interesses sociais, da coletividade, são frutos da união de interesses individuais que se despojam do seu egocentrismo para gerar um novo ente que é o interesse coletivo. ${ }^{12}$

No Direito brasileiro, doutrinadores como Ada Pellegrini Grinover (1984, p. 2) privilegiam o requisito da determinação do grupo para a caracterização dos interesses como coletivos quando os definem como interesses comuns a uma coletividade de pessoas e apenas a elas, mas ainda repousando sobre um vínculo jurídico definido que as congrega.

Parte da doutrina defende que os termos coletivo e difuso são sinônimos e sugerem a ideia de extensão, de aplicabilidade a muitas pessoas;

11 Por esse motivo, o Art. 81, III, da Lei n. 8.078/90, o Código de Defesa do Consumidor, considera inserido dentro do gênero de interesses transindividuais os interesses individuais homogêneos por decorrerem de uma origem comum.

12 J. Chevallier (1981, p. 901) discorreu com maestria sobre o tema: Les intérêts particuliers, qui gravitent dans la sphère privée, vont se trouver coagules, dans l'espace associatif, en intérêts collectifs, qui seront à leur tour agrégés, dans La sphère publique, pour former l'intérêt general; la transformation par de coalescence des intérêts particuliers en intérêts collectifs constitue une première forme de traitement et de filtrage des demandes sociales, qui facilitera la définition de l'intérêt general. 
o liame para esse posicionamento são os interesses metaindividuais, que transcendem a individualidade e podem alcançar a coletividade.

De outro lado, há o posicionamento de que a distinção é possível. Celso Bastos põe em relevo o fato de que os interesses coletivos

[...] dizem respeito ao homem socialmente vinculado, havendo portanto um vínculo jurídico básico, uma geral affectio societatis, ao passo que os interesses difusos se baseiam numa identidade de situações de fato, sujeitando-se a lesões de natureza extensiva, disseminada ou difusa. (BASTOS, 1981, p. 40).

O interesse difuso diz respeito a um universo maior que o coletivo; enquanto aquele pode abranger toda a humanidade, este possui um alcance menor por estar restrito a um vínculo jurídico e a uma relação de base, o que o faz reunir grupos sociais definidos. O interesse coletivo é o resultado da projeção corporativa do homem; o interesse difuso considera o homem como ser humano, sujeito de direitos.

Milaré, Nery Júnior e Ferraz, ao tratarem sobre os interesses difusos, consideram que,

desde que o homem ser social, se organizou em sociedade, passaram a existir certos interesses que não pertenciam a indivíduos determinados, mas, de modo geral, a toda a sociedade. Havia direitos da comunidade, que não eram propriamente direitos subjetivos, já que a comunidade em si mesma considerada não possuía personalidade jurídica, qualquer que fosse o sistema jurídico que estivesse examinando. (FERRAZ, 2001, p. 114).

Nesse rol de argumentos acerca dos interesses coletivos e suas divisões está inserido o fenômeno de crescimento do terceiro setor e sua estreita relação com a cidadania.

Em sua obra, José Eduardo Sabo Paes pontua:

O Terceiro Setor é aquele que não é público e nem privado, no sentido convencional desses termos; porém, guarda uma relação simbiótica com ambos, na medida em que ele deriva sua própria identidade da 
conjugação entre a metodologia deste com as finalidades daquele. Ou seja, o Terceiro Setor é composto por organizações de natureza "privada” (sem o objetivo de lucro) dedicadas à consecução de objetivos sociais ou públicos, embora não seja integrante do governo (Administração Estatal). (PAES, 2000, p. 56).

Na via de crescimento do terceiro setor, há de ser levantada a questão sobre as terminologias adotadas, pois ainda não possuem unanimidade, principalmente porque vários são os perfis, conceitos, missões, estruturas e finalidades das organizações, que vão desde ONGs, ${ }^{13}$ institutos, organizações filantrópicas, fundações, associações, OSCIPs, ${ }^{14}$ etc.

A expressão "terceiro setor" ainda é recente no Brasil, muitas denominações foram sugeridas, porém nenhuma conseguiu abranger a gama de instituições existentes em razão de suas especificidades e da complexidade do tema. Por conseguinte, o termo terceiro setor passou a ser adotado devido às suas características afinadas com o que se entendia por sociedade civil.

Percebe-se que todos os entes jurídicos de caráter não governamental, que não tenham fim econômico, que defendem a concretização dos direitos fundamentais, da cidadania e têm por escopo o bem comum, integram o universo do terceiro setor. Todavia, na contramão do crescimento do terceiro setor está a sua necessidade de legitimação, que se dá através da correta constituição jurídica e regular funcionamento das instituições.

Após a constatação, por parte do Poder Público, do Estado, da extrema necessidade de organização social, ocorreram mudanças significativas no modo de enxergar a atuação do terceiro setor e de delimitar a sua autonomia com base na Constituição de 1988.

$\mathrm{Na}$ esteira do que foi afirmado é imprescindível a formação de cidadãos que sejam capazes de aguçar o seu censo crítico para o que

13 ONG's - Sigla que significa Organizações não governamentais e advém do termo NGO - Non Governmental Organization. O termo surgiu no plano mundial na Carta das Nações Unidas, em 1945.

14 OSCIP’s - Qualificação específica para a organização social que atender aos requisitos da Lei n. 9.790 de 23 de março de 1999. 
ocorre no mundo do Direito e logicamente em sociedade. A formação se dá com os movimentos sociais que, no Estado Democrático, funcionam como bússola para identificar e construir a devida crítica ao foco dos problemas que afetam a coletividade, para propor alternativas na forma de políticas públicas, para fortalecer os ideais democráticos e criar uma consciência social de direitos e obrigações.

É importante construir a cidadania para encontrar num homem ou mulher muito mais do que um simples indivíduo e sim um legítimo intérprete da Constituição. ${ }^{15}$ Esse cidadão se encontra de fato, em sentido oposto a todo o sistema; é o verdadeiro titular dos direitos e garantias descritos na Lei maior e detém o poder de oposição ao próprio Estado sempre que este o contrariar.

Sobre a necessidade de participação e não de mera representação do povo num governo democrático como meio de exercício dos direitos da sociedade que o compõe, Casquete traça importantes observações:

Com una conceptualización tal, la democracia se ve relegada las más de las veces a la condición de mero método com ciudadanos apáticos (uma contradictio in terminis) como protagonistas que delegan y dejan hacer a los profesionales de la política, em lugar de ser concebida como um mecanismo para regular coletivamente la convivencia entre indivíduos que se perciben a sí mismos como al momento de la escenificación ritual del mito democrático que son las elecciones, con los partidos políticos como actores estelares; al margen de esta ocasión esporádica, la mejor contribucíón que cabe esperar de los ciudadanos es su aquiescencia y complicidad como meros espectadores, nunca como agentes efectivos, esto eficaces

15 Conforme Häberle (2002, p. 37), “Povo” não é apenas um referencial quantitativo que se manifesta no dia da eleição e que, enquanto tal confere legitimidade democrática ao processo de decisão. Povo é também um elemento pluralista para a interpretação que se faz presente de forma legitimadora no processo constitucional: como partido político, como opinião científica, como grupo de interesse, como cidadão. A sua competência objetiva para a interpretação constitucional é um direito da cidadania no sentido do art. 33 da Lei Fundamental (NT 8). Dessa forma, os Direitos Fundamentais são parte da base de legitimação democrática para a interpretação aberta, tanto no que se refere ao resultado, quanto no que diz respeito ao círculo de participantes (Beteiligtenkreis). Na democracia liberal, o cidadão é intérprete da Constituição! 
políticamente, corresponsables y copartícipes en el diseño de um provecto societal determinado. En consecuencia, siempre desde este punto de vista que desconfia de las potencialidades de la ciudadanía organizada, la participación em la cosa pública quedaría relegada a um momento puntual em el tiempo, precisamente es, como sujetos políticos. (CASQUETE, 2006, p. 2-3). ${ }^{16}$

A legislação brasileira comprova essa grande área de atuação, a começar pela Constituição de 1988 que possui um notório caráter social e é retrato de todo um processo de mobilização e mudança nas direções legislativas ao assegurar em seu texto grandes conquistas como os princípios elencados no seu artigo $5^{\circ}$, a descentralização da competência do Estado para a promoção de políticas públicas focadas nas questões sociais, os direitos de cidadania política como espelho dos intensos movimentos políticos à época da Carta de 1967 e como ápice o direito de livre associação, que é o enfoque jurídico delineado na lei maior para a atuação legítima do terceiro setor na cidadania.

Uma cidadania organizada se mostra sob as formas de processos sociais participativos, distintos do exercício da cidadania individualmente considerada, por mais que esta também tenha sua razão de ser. Organizar traduz um aspecto importante da competência democrática por coerência participativa, bem como por estratégia de mobilização e influência da sociedade, e essa mobilização se dá também com a formação da opinião pública que, com o devido acesso às oportunidades educacionais colocadas ao alcance das coletividades, pode proceder a uma avaliação

\footnotetext{
${ }^{16}$ Com uma conceituação tal, que, na maioria das vezes, a democracia é relegada à condição de mero método, com cidadãos apáticos como protagonistas (o que significa, em termos, uma contradição), que delegam a políticos profissionais; em lugar de ser concebida como mecanismo para regular coletivamente a convivência entre indivíduos que se percebem a si mesmos como eficazes politicamente, corresponsáveis e copartícipes de um projeto social determinado. Em consequência, sempre a partir deste ponto de vista que desconfia das potencialidades da cidadania organizada, a participação na coisa pública ficaria relegada a momentos pontuais, precisamente no momento da encenação ritual do mito que são as eleições democráticas, com os partidos políticos como atores principais; à margem dessa ocasião esporádica, a melhor contribuição que se pode esperar dos cidadãos é sua aquiescência e cumplicidade como meros espectadores, nunca como agentes efetivos, isto é, como sujeitos ativos (Tradução livre).
} 
concreta da situação política e social capaz de apreender e julgar com equidade os fatos e encontrar as soluções.

Na esfera ordinária, há uma gama de legislações que solidificam a força do terceiro setor e sua estreita relação com a cidadania; no entanto, foi a partir da lei que dispõe sobre as OSCIPs, Organizações Sociais de Interesse Público, Lei n. 9.790 de 23 de março de 1999, que se constituiu o chamado "marco legal" do terceiro setor. A referida lei trouxe a possibilidade de as pessoas jurídicas, formadas por grupos de pessoas ou profissionais de direito privado sem fins econômicos serem qualificadas, pelo Poder Público, como Organizações da Sociedade Civil de Interesse Público - OSCIPs - e poderem com ele relacionar-se por meio de termos de parceria $^{17}$ desde que seus objetivos sociais e normas estatutárias atendam aos requisitos da lei.

O legislador não forneceu o conceito de Organização da Sociedade Civil de Interesse Público exatamente pela dificuldade real de encontrar a sua definição. Todavia, Luis Eduardo Patrone Regules, ao aprofundar os estudos na matéria, formulou a seguinte definição:

As pessoas jurídicas de direito privado, sem fins lucrativos, destinadas ao cumprimento de serviços de interesse público, colaboradoras da ação estatal nas áreas sociais definidas pela Lei 9.790/1999, criadas e geridas exclusivamente pelos particulares, qualificadas e continuamente fiscalizadas pelo Estado, sob a égide de regime jurídico especial - adoção de normas de direito privado com as derrogações originárias do regime jurídico de Direito Público (REGULES, 2006, p. 139).

O conceito formulado demonstra que a OSCIP funciona como meio para a consecução dos interesses públicos no Estado Social e Democrático

\footnotetext{
17 Termo de Parceria - Novo instrumento jurídico criado pela Lei no 9.790/99 em seu art. $9^{\circ}$, para a realização de parcerias unicamente entre o Poder Público e a OSCIP assim qualificada para o fomento e execução de projetos. Ele consolida um acordo de cooperação entre as partes e constitui uma alternativa ao convênio para a realização de projetos entre as OSCIPs e os órgãos das três esferas de governo, através de procedimentos mais simples do que os utilizados na celebração de um convênio.
} 
de Direito. ${ }^{18}$ As OSCIPs, assim como as demais organizações sociais, não revelam um fim em si, funcionam como instrumentos para que o cidadão atinja determinados resultados no campo social.

Embora o terceiro setor na atualidade não possua mais a visão de filantropia, o voluntariado é uma de suas maiores bandeiras no cumprimento da cidadania. Os fatores que permeiam a conduta de um ser humano a prestar um serviço sem qualquer retorno material são refletidos de forma direta no conceito de cidadania, pois ele participa de forma ativa dos assuntos de interesse da comunidade e da administração dos governos, com propostas para a solução dos mais diversos problemas que assolam a sociedade.

A origem do trabalho voluntário é tratada com propriedade na obra de Corullon e Barnabe:

Habitualmente, o voluntário é descrito como um fenômeno típico da América do Norte, intimamente ligado à formação local. Seria o resultado de um processo histórico que privilegiou a livre associação entre as pessoas em detrimento do poder coercitivo do Estado. De fato, parte importante da colonização em certas regiões dos Estados Unidos teve por base hordas de perseguidos que vinham se estabelecer no Novo Mundo como opção de sobrevivência. E foi necessário que essas pessoas se apoiassem mutuamente, desenvolvendo assim um sentido de comunidade que até hoje se reflete em iniciativas de interesse público, como é o caso do trabalho voluntário.

18 Op. cit., p. 23: Conforme Regules (2006, p. 139), o Estado Social se sobressai ao Estado de Direito e ao Estado Liberal: Com efeito, o Estado Social (ou de Bem-Estar Social) tem representado muito mais uma acumulação de características fundamentais em que são conservados os elementos básicos do Estado de Direito - do que a substituição ou derrocada deste último. Para alguns doutrinadores, o Estado Social surge para corrigir as deficiências contidas no Estado Liberal ou Estado de Direito clássicos, renovando-os, isto é, introduzindo novos elementos capazes de prover certas necessidades básicas dos seres humanos, jamais como substituição, insista-se, de um modelo pelo outro. É cediço que, enquanto o Estado de Direito busca erguer barreiras à atuação estatal - e também à dos particulares, o Estado Social fixa prestações positivas em favor da sociedade como um todo ou de segmentos da sociedade. Em síntese, a necessidade inadiável de se coibir o abuso do poder econômico, o alastramento da miséria e das desigualdades sociais, entre outras mazelas que afligem o homem em sociedade, impôs o surgimento de regras tendentes a estabelecer a intervenção do Estado. 
Já na América Latina, a colonização foi montada como empreendimento do Estado. Concomitantemente à chegada dos colonos, instalavam-se os aparatos burocráticos da Coroa Portuguesa, ou a Coroa Espanhola, juntamente com as estruturas hierárquicas do catolicismo. Dessa maneira, nossas sociedades moldaram-se identificando o espaço de atuação pública como sendo exclusivamente estatal ou religioso.

No caso específico do Brasil (o que vale igualmente para o Sul dos Estados Unidos), há que se acrescentar um outro fator: o sistema produtivo foi maciçamente organizado sob a forma de grandes plantações, movidas pelo braço escravo, e o escravismo parece ser exatamente a antítese das idéias de comunidade e de voluntariado.

Não obstante esses fatores adversos, o voluntariado tem raízes muito antigas e profundas no Brasil. Movem-nos três sentimentos que parecem se colocar acima, até mesmo, dos nossos condicionamentos históricos: a compaixão, a solidariedade e a indignação. (CORULLON; BARNABE, 2002, p. 23).

A Lei ${ }^{\circ} 9.608 / 98$, denominada lei do voluntariado, foi criada com o objetivo de disciplinar o trabalho voluntário, definido como atividade não remunerada prestada por pessoa física a entidade pública de qualquer natureza ou instituição privada sem fins lucrativos, sem gerar vínculo empregatício nem obrigação de natureza trabalhista.

A criação da lei procurou em primeiro lugar difundir a cultura do voluntariado e ao mesmo tempo proteger as instituições sem fins lucrativos de possíveis reclamações trabalhistas infundadas ou em desencontro com os ideais voluntários. Os artigos $1^{\circ}$ e $3^{\circ}$ da referida lei ratificam a afirmação exposta quando descrevem respectivamente sobre o termo de adesão ao trabalho voluntário que deve ser firmado entre a instituição e o voluntário e a possibilidade de ressarcimento das despesas que comprovadamente o indivíduo realizar no desempenho de suas atividades voluntárias expressamente autorizadas.

A Constituição Federal como reflexo de toda essa transformação da sociedade não delimitou apenas ao Poder Público a incumbência de perseguir o desenvolvimento e a justiça social; ela estendeu aos indivíduos isoladamente ou em grupo a possibilidade de desenvolver em suas atividades os objetivos fundamentais da República. 


\section{Conclusões}

Em síntese, as ações desenvolvidas pelas organizações do terceiro setor são sinônimas de cidadania, são claras extensões do Poder Público, não executadas pelo Estado, tampouco assumidas pelo mercado. Diante das urgentes demandas sociais, surge a relação estreita entre o terceiro setor, os interesses coletivos e o cumprimento da cidadania.

O Terceiro Setor surgiu como uma força proporcionalmente inversa à insuficiência do governo e do mercado na provisão dos bens públicos minimizou a ação do Estado e selou a ideia de democracia e desenvolvimento social.

Como reflexo desse processo, firmou-se como ator fundamental para o processo de construção da cidadania e defesa dos interesses coletivos; contudo, as questões sociais não são tão simples ou acessíveis, cada um dos setores possui o seu papel e a sua contribuição social e esses devem agir em igualdade de condições para que soluções viáveis sejam encontradas e por via de consequência sejam atendidas às demandas sociais.

É importante para esse contínuo crescimento a consciência de todos os participantes na interpretação da Constituição de que uma sociedade cidadã não deve existir apenas no texto da sua Lei maior. Como o art. $3^{\circ}$ da Constituição Federal de 1988, por exemplo, ela tem que ser edificada através da participação popular legítima, do apoio aos movimentos sociais, da educação dos homens, mulheres e principalmente crianças para entender e abraçar o que é ser uma sociedade livre, distribuída de modo menos desigual.

Ser justa e solidária é ter como metas o desenvolvimento nacional, a diminuição com vistas à erradicação da pobreza, da marginalização, das desigualdades sociais e regionais, a promoção do bem de todos, sem preconceitos de origem, raça, sexo, cor, idade, ou quaisquer outras formas de discriminação. Mencionar essa cidadania é reafirmar o direito de plena realização do indivíduo, do cidadão, da coletividade e da ocupação dos espaços da sociedade.

A justiça social tão proclamada depende do esforço conjunto do Estado, da sociedade e do terceiro setor. Esse esforço se descortina na 
efetiva concreção dos direitos fundamentais, sociais e, especialmente, dos direitos da coletividade insculpidos na Carta Magna que, para abraçar a realidade social, precisam deixar o campo da hipótese, não podem continuar sendo apenas uma proclamação solene de direitos não realizados.

\section{Referências}

BASTOS, C. A tutela dos interesses difusos no direito constitucional brasileiro. RePro 23. São Paulo: RT, jul./set.1981.

BOBBIO, N. O futuro da democracia: uma defesa das regras do jogo. 6. ed. Rio de Janeiro: Paz e Terra, 1986.

BOBBIO, N. Estado, governo e sociedade: por uma teoria geral da política. Rio de Janeiro: Paz e Terra, 1987.

BOBBIO, N.; MATTEUCCI, N.; PASQUINO, G. Dicionário de política. 10. ed. Brasília: UNB, 2000.

BONAVIDES, P. Curso de Direito Constitucional. 14. ed. São Paulo: Malheiros, 2004.

BURTZKE, A.; ZIENBOWICZ, G.; CERVI, J. R. O direito ao meio ambiente ecologicamente equilibrado. Caxias do Sul: EDUCS, 2006.

CASQUETE, J. El poder de la calle. Ensaios sobre acción colectiva. In: Coleccion Estúdios Políticos. Madrid: Centro de Estudios Políticos y Constitucionales, 2006.

CHEVALLIER, Jacques. L’association entre le public et le privé. Révue du droit public. n. 4,1981.

CORULLON, M. B.; G.; BARNABE, M. F. Voluntariado na empresa: gestão eficiente da participação cidadã. São Paulo: Peirópolis, 2002.

DALLARI, D. A. Direitos humanos e cidadania. São Paulo: Moderna, 1998.

FERNANDES, R. C. Privado, porém público: o terceiro setor na América Latina. 2. ed. Rio de Janeiro: Relume Dumará, 1994. 
FERRAZ et al. A ação civil pública e a tutela jurisdicional dos direitos difusos. In: BRANDÃO, P. T. Ações constitucionais: novos direitos e acesso à justiça. Florianópolis: Habitus, 2001.

GIDDENS, A. As consequências da modernidade. São Paulo: UNESP, 1991.

GRINOVER, A. P. Novas tendências na tutela jurisdicional dos interesses difusos. Rev. Curso Direito. Uberlândia, Univ. Fed. Uberlândia, n.13, 1984.

MANCUSO, R. C. Interesses difusos: conceito e legitimação para agir. 4. ed. São Paulo: RT, 1997.

MONTOVANELI JUNIOR, O. Políticas públicas no século XXI. Blumenau: Edifurb, 2006.

NUNES, A. Terceiro setor: controle e fiscalização. 2. ed. São Paulo: Método, 2006.

PAES, J. E. S. Fundações e entidades de interesse social: aspectos jurídicos, administrativos, contábeis e tributários. 2. ed. Brasília: Brasília Jurídica, 2000.

REALE, Miguel. O renascimento do liberalismo. In: MARTINS, I. G. $O$ Estado do futuro. São Paulo: Pioneira, 1998.

REGULES, L. E. P. Terceiro setor: regime jurídico das OSCIPS. São Paulo: Método, 2006.

RIFKIN, J. Identidade e natureza do terceiro setor. In: IOSCHPE, E. B. (Org.). $3^{\circ}$ Setor: desenvolvimento sustentado. São Paulo: Paz e Terra, 2005. ZANETTI JÚNIOR, H. Direitos coletivos lato sensu: a definição conceitual dos direitos difusos, dos direitos coletivos stricto sensu e dos direitos individuais homogêneos. In: AMARAL, G.; CARPENA, M. L. C. (Org.). Visões críticas do processo civil. Porto Alegre: Livraria do Advogado, 2005.

Recebido em: 07/01/2010

Revisado em: 17/03/2010

Aprovado em: 29/03/2010 